\title{
Journal of Gerontechnology \\ The iPad project: Introducing iPads into care homes in the UK to support digital inclusion
}

\begin{abstract}
Background There are an estimated 5,153 nursing homes and 12,525 residential homes in the UK with around 426,000 residents of whom $80 \%$ have some form of dementia or memory problem. Only $38 \%$ of staff working in residential and domiciliary services say they use technology in direct work with residents. Objectives (1) To explore the experiences and potential benefits and barriers of iPad use in 63 care homes for residents with dementia, their family/friends and care staff. (2) To develop recommendations based on different ways in which iPads can be used in care settings and what needs to be in place to support their successful introduction and usages. Method A mixed methods approach based on data from staff interviews and a self-administered questionnaire, resident case studies, family interviews and observation of activity sessions. Results The main findings were (1) iPads provided a flexible and adaptable means of engaging residents, their relatives and staff in both one-to-one and group sessions (2) iPads offered a new means to increase social interaction and resident engagement. Conclusion Systematic incremental implementation of the use of iPads in a care home can help promote digital inclusion for both residents and staff and participation by family members.
\end{abstract}

Key words: dementia; technology; digital inclusion; care homes; iPads 


\section{Background}

There are currently around 800,000 people with dementia in the UK, a figure that is predicted to grow to 1 million people by 2025 and to 1.6 million by $2040^{1}$. There are an estimated 5,153 nursing homes and 12,525 residential homes in the UK with around 426,000 residents $^{2} .80 \%$ of people living in care homes in the UK have some form of dementia or memory problem ${ }^{1}$.

The use of touchscreen technology has the potential to provide a positive impact on people with dementia in care home settings ${ }^{7}$. This research into touchscreen technology highlighted the use of iPads for group activities ${ }^{11}$ and found that it "can make a substantial contribution to helping people to live well with dementia".

In view of the above this paper sets out to explore the experiences and potential benefits of and barriers to touchscreen technology, based on a study using Apple iPads, use in care homes for residents with dementia, their family/friends, and care staff.

Dementia is likely to affect a person's ability to do certain tasks, which may change over time and could vary from day-to-day, potentially affecting their use of technology. It is important to recognise that people who develop dementia will increasingly have experience of using technology both for work and leisure. However, there is the possibility of lapse of use if people find it increasingly difficult to engage with the technology due to their condition. Many people with dementia will have other conditions and age related difficulties such as with hearing, vision and manual dexterity ${ }^{3}$.These aspects together with rapidly changing technology and the development of new apps, mean that any skills gap is likely to be exacerbated.

There is a myriad of apps targeted at specific disabilities and conditions including health apps which aim to help reduce stress and anxiety, aid concentration and enable a better allround sense of well-being. Additional examples include navigational aids and more leisurefocused apps, such as games. Many of these will be of use to people with dementia. Some studies have found that (assistive) technologies can help support independence and quality of life ${ }^{4}$, as well as promoting the enjoyment of games ${ }^{5,6,7}$.

Digital tablets pose learning challenges for older people that could be reduced if interface design better supported impaired cognitive processes such as memory and attention. Choice of tablet is therefore an important consideration ${ }^{8}$. Before being made available for use by people with dementia, applications should be carefully reviewed to assess their suitability, as a negative experience with an activity in the early stages of using a new technology could lead to its abandonment ${ }^{9}$.

Apps focusing on dementia are often aimed specifically at the people providing support, such as unpaid carers or health and social care staff. It has been found that working with carers and family member is the key to engagement ${ }^{6}$. However, most gerontechnology research has focused on developing technology to support people with dementia, with less focus on how family carers can be engaged and supported ${ }^{10}$. 
Providing activities in care homes can have many benefits, including helping to increase positive emotions and enabling people with dementia to remain occupied and involved ${ }^{7,11}$. The increasing availability and ease of use of touchscreen tablets raises a variety of possibilities regarding activities for people with dementia, but their use in care settings has been limited ${ }^{7}$.

Recommendations for the introduction of this type of technology stressed the need for training to improve implementation. Barriers to use included issues relating to cost, staff confidence, weight (although this is less a problem with newer iPads), reflection on the screen, Wi-Fi connectivity and holding the device ${ }^{7}$.

Approximately $60 \%$ of care homes in the UK do not offer a Wi-Fi internet connection for residents, and only $10 \%$ of those that do include it in the weekly room charge ${ }^{13} .25 \%$ of the care home staff spoken to did not know whether Wi-Fi was available to their residents or not $^{14}$.

In 2013 around 1.5 million people were reported as being employed in adult social care (including care homes) and this may rise by between $20 \%$ and $54 \%$ by $2025^{15}$. It has been shown that the use of technology can have a positive benefit on staff in health settings including care homes. The Get Connected programme ${ }^{16}$ was devised to stimulate ICT use in social care, and particularly to improve access for service users in the residential and day care sectors. For staff with little or no prior experience of technology, the introduction of computers helped them to develop their digital skills and overcome some of their fears about technology, as well as increase the use of technology in care homes and support residents in their use of technology

$85 \%$ of employees in residential and domiciliary care have access to at least one form of digital technology when at work, but only $44 \%$ of employees use them every day, and only $38 \%$ say they use them in direct work with people using services. Digital technology may be well embedded for professional and managerial staff, but not for the remainder of the workforce $^{17}$.

However, there are a number of barriers to the deployment of technologies for use by professionals, which could affect use in care homes. These include lack of usability; problems with access to the health IT applications; low computer literacy in patients and clinicians; insufficient basic formal training in health IT applications; physicians' concerns about more work; workflow issues; problems related to new system implementation, including concerns about confidentiality of patient information; depersonalization; and incompatibility with current health care practices ${ }^{18,19,20}$.

Whilst there is some convergence over recent years between mainstream and assistive and health care technologies (digital health, mobile health, telecare and telehealth for example), the landscape is still disparate and fragmented for the end user. All of these factors mean that anyone supporting people with dementia in the use of technology will need to have good, up-to-date digital skills. Access to technology and/or the internet does not translate into use if support is not available ${ }^{6}$. 


\section{The iPads project}

In 2011 xxxxx, England's largest not-for-profit provider of care and housing for older people, specialising in dementia care, set out to explore how they could use technology to enhance their existing activity provision within their care homes, primarily for residents living with dementia.

This led to the development of an innovative programme to introduce iPads across all of Xxxxx's care homes, supported by a comprehensive one day training programme for Activity Co-ordinators (ACs). The programme included data protection, confidentiality and security of data, iPads basics, apps and folders, maintenance and ways of using the iPad with residents. Participants were required to design and present a one hour activity session using iPads. Post-training support included a help desk and a forum to share good practice and issues.

The technical specification of the Apple iPads version 4 capacity $16 \mathrm{Mb}$ with iOS 7 operating system used in the programme and purchased in 2014 was as follows. Size and weight (excluding the toughened protective case) was height: $241.2 \mathrm{~mm}$ (9.50 inches); width: 185.7 $\mathrm{mm}$ (7.31 inches); depth: $9.4 \mathrm{~mm}$ (0.37 inches); weight: $652 \mathrm{~g}$ (1.44 pounds). The display was 9.7-inch (diagonal) LED-backlit multi-touch display with $2048 \times 1536$ resolutions at 264 pixels per inch (ppi).

Xxxxx implemented the iPad project primarily through their existing network of dedicated ACs employed in each home to provide emotional and cognitive stimulation for residents through regular activity and engagement sessions.

The iPads were introduced in 8 phases over 2 years. In Phase 1 there was an initial trial of one iPad in one care home. In Phase 2 the iPad training package was developed and subsequently delivered in Phase 3 to ACs in 20 care homes. The training package was updated in Phase 4 and in Phase 5 was delivered to ACs from a further 43 care homes. During Phase 6 there was an internal evaluation of iPad usage by means of a staff feedback survey and Phase 7 was a consolidation period. This paper reports on the final phase of the process, the external evaluation of the iPad project.

\section{Research methods}

The $x x x x x x$ was commissioned to conduct an independent evaluation of the iPad project.

The two main objectives were to:-

1. Explore the experiences and potential benefits of and barriers to iPad use in care homes for residents with dementia, their family/friends, and care staff.

2. Develop recommendations based on the different ways in which iPads can be used in care settings and what needs to be in place to support their successful introduction. 
The research team adopted a mixed methods approach based on data from interviews, case studies, surveys and observation, which took place between October 2014 and March 2015. This approach is described in more detail below. Approval for the research was granted by an Ethics Committee at xxxxx.

\section{Study Procedures}

\section{Survey of Activity Co-ordinators}

An online survey was developed to elicit the experiences and opinions of the ACs working across the $63 \mathrm{xxxxx}$ care homes where the iPads had been introduced. The survey was created on Survey Monkey ${ }^{\circledR}$ with pdf and Word versions also generated to make completion easier for some staff who may have had limited online access. The survey was designed to take approximately 20 minutes so that it would not impinge greatly on staff working in a busy care setting. It was distributed to the ACs by xxxxx through their existing email network.

The survey comprised 24 questions focusing on five overarching topics and a range of subtopics as set out below:-

1. Previous IT skills and experience of using iPads

- Self-rating of IT skills (poor/average/good/very good);

- Experience of iPad use and whether they used them at home and/or work before and since the start of the project (none/a little/some/ a lot);

- Whether they attended training (yes/no) and if it met their needs (open question);

- Confidence in using the iPads before and after the training and at the start of the project (not at all confident/somewhat confident/confident/very confident).

2. How iPads are used within the care homes

- How they used the iPads at work (one to one sessions/small groups under 5/larger groups);

- Whether they have replaced other activities (yes/no/open comment);

- Who they have involved (family members, managers, other staff);

- How often they use them (once a month/once a week/once a day).

3. The perceived impact of using iPads

- The impact of the iPads in terms of changes in:-

- Residents' mood, anxiety and behaviour (yes/no for each option with open comment);

- How the ACs engaged with residents, family members and other staff (yes/no/open comment);

- How other staff engaged with residents, family members (yes/no/open comment);

- How the ACs engaged with residents, family members and other staff (yes/no/open comment).

4. Barriers and challenges encountered

- What has worked well and not so well when using the iPads (open comment); 
- Practical and technical difficulties (iPad not available/iPad not charged/glare or reflection on iPad screen/screen too small/ customer's health conditions affect ability to use iPad e.g. eyesight, hearing, manual dexterity, frailty).

5. The planned use of iPads in the future (open comment).

Hard copy returns of the survey were entered into Survey Monkey ${ }^{\circledR}$ by a researcher to ensure consistency of the format of the data collected. Quantitative responses to the questionnaire were analysed in a Microsoft Excel spreadsheet. The analysis included frequency counts and descriptive statistics capturing data from the five overarching topics listed above. The use of an advanced statistical analysis package such as SPSS was not required due to the nature of the quantitative data being not sufficiently complex. Qualitative responses were analysed for content using a thematic approach.

\section{Care home case studies}

Four care homes were offered as case study sites by the care home organisation. These were selected as examples of good practice in digital inclusion. Each site was visited by two members of the research team. Prior to the visits, project information sheets and consent forms were sent to each home to ensure that potential participants were fully informed about the research.

During each visit it was planned to collect data using the following methods:

- Interviews with the AC in each home;

- Interviews with staff members from the wider team (up to four per home);

- Interviews with relatives (up to two per home were invited, for example by a poster advertising the opportunity to participate, however there was limited uptake);

- Observation of an activity session.

Finally, an additional interview was carried out with the iPad project lead for xxxxx to explore the phased introduction of the iPads, the provision of training and support, and plans for the project moving forward.

All interviews were audio recorded and transcribed by the research team. Content analysis was used by the research team as the method of organising data into themes. The qualitative analysis was carried out manually rather than using a bespoke qualitative data analysis computer software package as the volume of qualitative data collected from the survey was low and as was intended due to respondents' time constraints. Emerging themes were cross-checked and verified by the researchers present at the interviews to clarify interpretations of respondents' meaning.

\section{Results and analysis}

The findings presented in this section combine the AC survey responses, the information gathered from the interviews and observations during the visits to the four case study care homes, and a final interview with the Xxxxxx iPad Customer Engagement Adviser. Overall, 48 ACs responded to the survey, a response rate of $76 \%$. All survey statistics reported are based on the 48 responses unless otherwise specified. For example, if four 
ACs did not answer a particular question, the result will be followed by $(n=44)$ to indicate this.

\section{Overall usage}

The initiative to introduce iPads resulted in a reported five-fold increase in their use in activity sessions. $15 \%$ of respondents said that they had used iPads prior to the initiative, a figure that increased to nearly $80 \%$ at the end of the project. The iPads had also become well-established in the majority of care homes with $80 \%(n=44)$ of ACs saying that they had been using iPads in their care homes for at least six months.

\section{ACs' skills, experience and confidence with iPads}

Prior to the project $13 \%$ of ACs rated their general computer/IT skills as worse than average, $37 \%$ as average and $50 \%$ as better than average. In terms of use of an iPad $31 \%$ of ACs reported that they had no experience, $25 \%$ had a little, $25 \%$ had some and $18 \%$ had a lot of experience.

Following the training, self-rated confidence in using the iPads increased considerably with a further improvement being seen after the ACs had been able to use the iPads in practice with $3 \%$ reporting that they were not at all confident, $11 \%$ somewhat confident, $15 \%$ confident and $17 \%$ very confident (Figure 1 ).

-Insert Figure 1 here

Confidence was also high in terms of ACs feeling able to share their newly-gained knowledge with other staff; $65 \%$ of respondents felt 'confident' or 'very confident' about showing other members of staff how to use the iPads with residents.

\section{How the iPads were used}

The content and structure of activity sessions varied between care homes. For example, some homes had set schedules of activities while others took place on a more ad-hoc basis. Group sessions were generally more formalised than one-to-one activities due to the organisation involved in getting multiple residents together at the same time.

In 98\% ( $n=41$ ) of cases, iPad-related activities were additional sessions or incorporated into existing activity sessions, rather than replacing 'traditional' activities. While in some cases this incorporation may relate to digitising an activity such as bingo, additional comments indicated that the iPads are helping to enhance activities and further enrich residents' lives by providing an extra dimension to an activity. This could be as simple as playing background music, taking photographs or the ad-hoc finding of pictures to support reminiscence or discussions

ACs may plan to run a session in a particular way, but if the residents do not respond positively at the time they will adapt and do something else instead. As one AC said, "I can plan it but when I get there it is a different story", and activities may start out as one thing and end up as something different. Even within a session there is a need to be flexible as 
"when you get there the conversation can go onto a different subject" and the session can go off on a tangent. The iPad can help to support this by providing the ACs with multiple different activities and options at their fingertips. Equally, a session may have been planned around the iPad but its use will actually depend on the residents and what they want to do at the time, and the iPad may not fit with this.

Use of iPads with residents, as measured post-training, varied across the ACs in terms of frequency with $42 \%$ using the iPad less than a few times a week, $44 \%$ a few times a week and $13 \%$ more than a few times a week. The timing of sessions also varied. Some ACs focused on afternoons, evenings and/or weekends, while others try to use the iPads everyday throughout the day.

\section{Session participation}

$56 \%$ of ACs involved a total of more than ten residents in their various iPad-related activities. Some residents did not engage with activity sessions in general, while others were not interested in the iPads or were not comfortable with them as "it's scary for some people". For some ACs, participation in an iPad session depended on who happened to be in the lounge at the time, while others referred to their 'regulars' who were more willing to use the iPad than other residents.

Those residents who took part had a variety of care needs, such as dementia, learning disabilities or mobility issues, indicating that the iPad activities are suitable and accessible for many different residents and can help to promote interaction. Unifying activities were felt to be especially positive when a home had different units for residents with different requirements, promoting contact and understanding between groups.

$46 \%$ of ACs involved family members in their sessions, which included joining in a quiz, musical-based reminiscence or the use of Skype for remote contact. As well as making them feel included in their loved ones' lives, they can provide important information about the residents and an insight into their past which helps with reminiscence activities. $50 \%$ of ACs involved other staff, $27 \%$ involved managers and $19 \%$ involved visitors. This wider involvement may have the added impact of improving digital skills across a range of support and stakeholders.

iPads were used in a variety of types of interaction ( $85 \%$ one-to-one, $75 \%$ small and $52 \%$ large groups) by the ACs. There was also variability in terms of who controlled the iPad, with residents being able to use the iPads supervised by the $A C(58 \%)$ and unsupervised (10\%). In other cases the iPad was controlled in sessions by the AC on $38 \%$ of occasions and $27 \%$ by another member of staff.

It was felt by one $A C$ that to enable direct interaction with an iPad it was preferable to focus on one-to-one activities. However, by connecting the iPad to a bigger television screen they could enable multiple residents to engage with a single iPad at the same time.

\section{Types of activity}


The ACs used the iPads to carry out a range of different activities (See Fig 2 below), with playing music or songs being the most common across a large majority Activity Coordinators (94\%). Games were also quite popular (58\%), with bingo, jigsaws, crosswords and quizzes being mentioned in particular; drawing and art, use of Skype and playing film clips were all used by between $45 \%$ and $60 \%$ of ACs.

Additional activities included:

- Using sensory apps such as fishing, water sensation and sounds (including animal noises);

- Reminiscence activities, in particular using Google maps to find images of where residents used to live;

- Viewing videos via YouTube, although it was not specified which types of clips were used;

- Using the camera function to take photographs and videos of various events, which can be shared with relatives or used on notice boards within the home;

- Use of a translation tool to help communicate with residents who may have reverted to their mother tongue, which is a symptom of dementia for some people;

- Online shopping, sometimes for actual shopping and sometimes as the basis for a more general conversation about different items;

- Use of Skype for video chat and voice calling enabled residents to stay in touch with relatives who are in different countries, too far away to visit frequently, or unable to visit for other reasons.

In addition to activities with residents, the iPads were used by the ACs and other staff as a means of accessing the internet to find out information. For example, when ACs planned activities such as quizzes and when staff needed to do their own research in response to any queries that may arise from their work.

\section{Assistance and problem solving}

While some ACs were able to resolve or work around any issues they encountered when using the iPads, others required assistance. 3 Customer Engagement Advisors, each covering two geographical areas, took on a support role with responsibility for approximately 25 to 30 ACs.

The iPad forum was established to provide a means for ACs to share ideas and to help with problem solving and trouble shooting. The iPad project coordinator felt that "the uptake was really great and we have seen some great ideas come through that".

However, the evaluation findings suggest that many ACs were more likely to try and resolve their problems by using the internet than the iPad forum. $56 \%$ of ACs found the iPad forum helpful or very helpful, no one found it unhelpful but $26 \%$ did not use the iPad forum and $14 \%$ were not aware of it. This suggests that more promotion is needed concerning the iPad forum and how it can be used by the ACs. 
Although knowing that the iPad forum is there if needed was enough for some ACs, others realised that they could use it more than they do currently, "I should do, but I don't". The main reasons for this were lack of time and lack of internet access to the online forum.

\section{Residents' experience with iPads}

Some residents were already using iPads when they arrived at their care home. This is likely to become more prevalent in the future as more residents come into care homes already familiar with this technology and relatives start encouraging their use. Examples from the case study sites include the following:

- One resident who was deaf and had very limited vision used their own iPad to communicate with others as they are able to read text on the screen when it is displayed in a large font. The iPad is useful because the background and contrast can also be adjusted to make the text clearer. The AC used a Bluetooth keyboard to let the resident know what is being said in conversations around them, which helped them to feel more engaged and independent;

- One resident had an iPad which they used to keep in touch with their family via email. A member of the wider staff team supported the resident as they learned how to use email;

- One resident used their iPad to write down their 'memoirs' which they shared with the AC who printed copies to put on the home's notice board. This gave the resident something to focus on and an opportunity to share their thoughts with others on their own terms, as they didn't take part in group activity sessions in the lounge. They had the text enlarged on the screen to make it easier to see and use, but would have liked to learn how to use the iPad more efficiently as "there must be a quicker way, but I haven't found it" and "there's so many things I'd like, I'm just on the cusp of grasping these things";

- One resident sometimes brought their own iPad when other sessions were taking place and used it independently in the background. A member of staff supported them and engaged with them while they were doing this.

Although these activities did not always involve the AC, they present different challenges as they may require a different skill set or more detailed knowledge of the iPad for the $A C$ to provide the appropriate support for each resident.

\section{Discussion}

In general, a variety of activity sessions were observed which involved an iPad in some way. These generally fell into three main categories:

1. Practical activities such as baking, knitting, massage or exercise sessions. The iPad cannot replace this type of activity, but may be used as a tool to support or enhance 
the activity. For example, it is used to play music in the background, "even when we have events we put a selection of music on in the background";

2. 'Converted' activities such as jigsaws, drawing/painting or quizzes, where the activity has been converted into a format that can be run on the iPad. The iPad may provide a better way of running the activity that requires less space, fewer resources, and allows more people to get involved at one time;

3. iPad-specific activities such as the 'fishpond' app and other sensory apps. An iPad is necessary for this type of activity as there is no 'real' equivalent.

There was a good balance across and within the homes in terms of providing activities of all three types, which helps to address the needs and preferences of different residents. The type of activity and use of the iPad may depend on the individuals involved. For the ACs, this may depend on knowledge of how the residents will respond to the iPads, their skill level and how comfortable and confident they are using the iPad. This may improve the more they use the iPad and learn about its functions and limitations.

For individual residents, levels of use may depend on how they feel during a session and whether they want to engage with the iPad at that particular time or at all. For people with dementia concentration and attention span may fluctuate from day-to-day or over the course of a day, or decrease over time. The use of an iPad can promote flexibility to meet the changing needs of individual residents. Overall usage may change over time as residents become more familiar with the iPad and technology in general.

In terms of the wider staff team, this may depend on their specific role and the opportunity to engage with residents. Some staff may see activities as part of their caring role, while others focus on front-line care, and some are not confident using the iPads. This indicates the need for appropriate training in the use of iPads and how specific activities can be implemented. Staff usage will depend to some extent on the care home manager and how supportive and encouraging they are of the ACs, and the example they set for the staff team. Organisational characteristics including policies, incentives, technical support and budgets are key factors which influence levels of management support for digital approaches.

\section{Benefits and barriers}

A range of benefits and barriers to the introduction and use of iPads in care homes were identified in the study. These are summarised in Table 1 and discussed further below.

\section{Benefits}

\section{Ease of use}

The touchscreen element of iPads is relatively simple to learn, and may need less dexterity or grip than holding a pen or paintbrush, which allows residents to take part in activities using a single finger. The interface can be configured to include only apps that are relevant 
to the individual, which has distinct advantages in the context of working with people who have significant memory problems. Additional extras such as a stylus, paintbrush or keyboard are available, providing a range of options to suit individual needs and preferences. Similarly, adjustments can be made to font size, colour and contrast to match the abilities of each resident.

As it is relatively easy for most residents to use an iPad, it can help them to maintain control and give them the ability to make their own choices. iPads will be new to most residents, and so may retain the novelty value for some, particularly as they can be used in many different ways.

\section{Convenience and flexibility}

The iPad is a convenient way of providing access to a range of materials, resources and activities through a single portal, reducing the need for multiple media such as paper, CDs, board games, craft equipment and DVDs. Additional flexibility can be provided by connecting the iPad to a television (via cable or wi-fi for example), which enables groups of residents to see the iPad screen at the same time and with a larger image. The iPad interface supports rapid movement between different apps and activities, which allows the $A C$ to respond to ad-hoc needs or preferences of individuals as they arise.

\section{Portability}

An additional aspect of the iPad which makes it particularly useful in care homes settings is its convenient size and weight. This enables the AC to take the activity to the residents, especially those who are bed-bound or less mobile, or those who may be more reserved and less willing to join in group activities. It can also be passed around between residents in a group, allowing each resident to have a turn.

\section{Cost}

Once the initial purchase has been made, an iPad provides a relatively cheap way of trying out new activity ideas, especially when many apps are free and the need to invest in a physical DVD, game or other form of resource is avoided.

\section{Barriers}

\section{Ease of use}

It was observed in some sessions that the sensitivity of the touchscreen on the iPad was sometimes problematic. For example, some residents put their thumbs on the front for support when they were holding the iPad. This action held the focus of the touchscreen, preventing any subsequent movement with another finger from registering. Similarly, the touchscreen functionality was also affected when a resident rested a finger or knuckle on the screen or tapped the screen by accident. This can be frustrating and confusing for some residents, especially if they accidentally tapped a button that changed the appearance of screen. At one care home an AC noted that a volunteer was not confident with technology in general and the iPad "just frightened her too much". 


\section{Convenience and flexibility}

Whilst the iPad may present flexibility and choice, knowledge of what is available, useful and effective in terms of technology for people with dementia and care staff is often limited $^{21}$.

\section{Portability}

The iPad can feel heavy to some residents (although newer versions are lighter), and the toughened case which was used in the homes where the study took place, while providing protection, makes it heavier and bulkier. This could potentially be an issue for frailer residents, although it should be noted that it was used successfully by a variety of residents in the sessions observed by the research team. Other touchscreen devices may be lighter or a smart phone could be an alternative solution.

One potential drawback of the portability of the iPad is the small size of its screen and speakers, which can limit accessibility for some residents. Many ACs addressed this by connecting the iPad to the television or using a small set of speakers, which requires the use of a suitable cable. Larger touchscreen devices such as a table top device may also provide an alternative solution

\section{Cost}

Other tablet devices are available which are cheaper and have similar functionality, and therefore could be even more cost effective than the iPads. Indeed, some participants in the evaluation suggested that a larger number of a different type of tablet could be purchased for the same price, which would increase availability across each care home.

Decisions concerning cost and the choice of tablet also need to take into account the availability of apps across different operating systems and platforms. Based on their experiences with other tablets and devices, the ACs felt that some apps and tools were more suitable on a non-Apple platform. For example, some music apps on Android were felt to have some advantages and could be used successfully in this setting without the accompanying video.

Although many ACs felt that they would not want to be without the iPads after having had the chance to use them, they recognised that there were some potential disadvantages to introducing technology into their activity sessions such as those relating to ease of use, convenience, flexibility and portability and cost as described above.

\section{Conclusion and Recommendations}

This study has explored the impact and benefits of adopting a systematic approach to promoting digital inclusion in care homes through the introduction of iPads, backed by a comprehensive programme of staff training and support. This was associated with in an increase in their use of 29 percentage points for care planning and the internet and of 65 percentage points for activity sessions. 
iPads provide a flexible and adaptable means of engaging with residents, their relatives, and other members of staff in both one-to-one and group sessions. Successful use of iPads as part of structured activity sessions requires ACs to have detailed knowledge of participating residents. This enables them to use the iPad in a way that acknowledges and addresses individual and group needs and preferences. Taking part in activities can also provide an ideal opportunity for staff to get to know residents better in an informal setting.

Data collected from observation and interviews suggests that iPads have the potential to increase levels of social interaction and engagement, as well as helping to reduce agitation and increase enjoyment for people living with dementia. For example in the final case study the $A C$ reported that an iPad was used with an "aggressive" resident to help calm and distract them." The evaluation indicates that this type of touchscreen technology can enhance and complement the provision of activities in care homes while also enabling a more person-centred approach to supporting residents.

This research also suggests that an iPad programme can enable a range of stakeholders to use technology either for the first time and/or in ways they had not used it before and thus become digitally included. This is much in line with the Get Connected scheme evaluation report (2012) ${ }^{16}$ which concluded that "high level commitment to digital inclusion is a crucial requirement if the use of new technologies is to flourish in care settings. The attitude and leadership of care managers is therefore crucial in enabling digital inclusion to become embedded in a sustainable way".

The learning that has emerged from this project provides valuable insight into how iPad technology can be used in care settings to provide positive experiences for residents and staff. As more people enter care homes with digital skills there will be a need to support people to maintain their existing skills as well as develop new ones. Findings from this study indicate that this might best be achieved by management enabling a comprehensive training programme, good flexible technical support and adequate infrastructure and equipment. These findings may in general apply to other touch screen tablets.

The findings from this study had led to the development of the following recommendations for the successful implementation of an iPad programme in care home settings.

\section{Comprehensive IT infrastructure}

The ability to use the diverse range of features that an iPad offers as an aid to maximising care home activities is dependent on a comprehensive technical infrastructure that includes good quality $\mathrm{Wi}-\mathrm{Fi}$ and/or the use of tablets with sim cards. This is crucial to maximising the effectiveness of the iPad in promoting beneficial activities, allowing the download of specific apps and providing the ability to update the operating system.

Some apps can affect battery usage, particularly if the screen needs to be on or open all the time when a video is running. Careful consideration should therefore be given to the addition of a docking station that allows the iPad to be recharged while it is being used. 


\section{Training and support}

ACs and other care home staff are likely to have varying levels of skills and experience in using iPads and other forms of technology. A comprehensive and ongoing programme of training and support is therefore necessary and might include specific training in the use of iPads to support residents with dementia.

\section{Availability of iPads}

It is important to assess the number of iPads that are required in each care home in order to maximise their use and benefit. This will depend on a range of factors including the number of residents, the abilities and preferences of the residents and the nature of activity provision. The use of iPads can offer convenience and flexibility for staff with the potential to better meet the needs of individual residents. Staff should always have a back-up plan when planning activity sessions.

\section{Staff Roles}

Allocating primary responsibility for iPad storage, usage and maintenance to one member of staff can help avoid problems such as double bookings, lack of charge and mislaid accessories. Supporting a range of staff to use iPads allows higher levels and greater flexibility of use.

\section{Limitations of the study and ideas for future research}

The learning points and conclusions from this study are based on data collected from 63 different sites run by one care home provider. Other care homes in the provider's group will have varying levels of use of technology and their experiences may differ from those in the study, as will those of other care homes not in the group.

Future studies could focus on more baseline measurement and monitoring of stakeholders' technology skills over a two to three-year period with a view to informing development of staff training and care plans. Consideration could be directed at developing and maintaining digital skills and ensuring staff know how to best support residents with this. Future studies should use appropriate control groups (and it would be ideal to try assessing comparative effectiveness of different tablets) so that causal statements are possible about tablet use.

\section{Acknowledgements}

The authors would like to thank everyone who took part in the evaluation activities. We would also like to acknowledge the efforts of the Xxxxx staff in improving the response rate for the initial survey.

\section{References}

1. Alzheimer's Society. Dementia 2014 report statistics. 2015; https://www.alzheimers.org.uk/info/20025/policy_and_influencing/251/dementia_uk; retrieved January 27, 2017 
2. Age UK. Later Life in the United Kingdom. 2016;

http://www.ageuk.org.uk/Documents/ENGB/Factsheets/Later_Life_UK_factsheet.pdf?dtrk1 =true; retrieved January 27, 2017

3. Tinder Foundation. Dementia and Digital: Using Technology to improve health and wellbeing for people with dementia and their carers. 2016;

https://www.goodthingsfoundation.org/sites/default/files/research-

publications/dementia_and_digital.pdf; retrieved January 27, 2017

4. Minocha S, McNulty C, and Evans S. Imparting digital skills to people aged 55 years and over in the UK. 2015; http://oro.open.ac.uk/44009/; retrieved January 27, 2017

5. Astell A, Joddrell P, Groenewoud H, de Lange J, Goumans M, Cordia A, and Schikhof Y Does familiarity affect the enjoyment of touchscreen games for people with dementia? International Journal of Medical Informatics 2016; 91:e1-8. doi:

10.1016/j.ijmedinf.2016.02.001

6. Tinder Foundation. Health and Digital: Reducing Inequalities, Improving Society. 2016; https://www.goodthingsfoundation.org/sites/default/files/research-

publications/improving_digital_health_skills_report_2016_1.pdf; retrieved January 27, 2017

7. Upton D, Upton P, Jones T, Jutlla K, Brooker D. Evaluation of the impact of touch screen technology on people with dementia and their carers within care home settings.

Department of Health West Midlands 2011;

http://79.170.44.96/lifestorynetwork.org.uk/wp-

content/uploads/downloads/2012/11/evaluation-of-the-impact-of-the-use-of-touchscreentechnology-with-people-with-dementia-.pdf; retrieved June 2017

8. Wright P. Helping older adults conquer digital tablets. Gerontechnology 2016; 14, 2, p7888; doi: $10.4017 / g t .2016 .14 .2 .005 .00$

9. Zhang S, McClean S, Nugent C, Donnelly M, Galway L, Scotney B. A predictive model for assistive technology adoption for people with dementia. IEEE J Biomed Heal Informatics 2014; 18, 1, p375-383

10. Kort H (2014). Dementia and dementia research. Gerontechnology 2014; 12 , 3, p125126; doi: 10.4017/gt.2014.12.3.002.00

11. Leng F, Yeo D, George S and Barr C. Comparison of iPad applications with traditional activities using person-centred care approach: Impact on well-being for persons with dementia. Dementia 2014; 13, 2, p265-273; doi: 10.1177/1471301213494514

12. Tyack C, Camic, P, Heron, M.J, Hulbert, S. Viewing Art on a Tablet Computer: A WellBeing Intervention for People With Dementia and Their Caregivers, Journal of Applied Gerontology 2015; doi: 10.1177/0733464815617287 
13. Age UK. The digital inclusion of older people in care homes: Learning and good practice from Reach for IT. 2015;

http://www.ageuk.org.uk/Documents/ENGB/Forprofessionals/Services\%20for\%20Later\%20 Life/ID200921\%20Digital\%20Inclusion\%20In\%20Care\%20Homes\%2024ppA4.pdf?dtrk=true; retrieved January 27, 2017

14. Citizens Advice Bureau. Hidden charges in care homes Exploring consumer protections within the care home market. 2015;

https://www.citizensadvice.org.uk/Global/CitizensAdvice/Public\%20services\%20publication s/Hidden\%20charges\%20in\%20care\%20homes.pdf; retrieved January 27, 2017

15. Age UK. Digital Inclusion Evidence Review. 2013;

http://www.ageuk.org.uk/Documents/EN-GB/For-

professionals/Research/Age\%20UK\%20Digital\%20Inclusion\%20Evidence\%20Review\%20201

3.pdf?dtrk=true; retrieved January 27, 2017

16. NIACE. Get Connected Impact Evaluation. 2012;

http://shop.niace.org.uk/media/catalog/product/1/2/120404_final_report_-

_get_connected_impact_evaluation.pdf; retrieved January 27, 2017

17. Dunn S and Braddell A. Digital capabilities in the social care workforce: Rapid Evidence Review. 2014; http://www.skillsforcare.org.uk/Document-library/NMDS-SC,-workforceintelligence-and-innovation/Research/Digital-literacy/Digital-Capability-Rapid-EvidenceReview-300714-FINAL.pdf; retrieved January 27, 2017

18. Finkelstein J, Knight A, Marinopolous S, Gibbons M, Berger Z, Aboumatar H, Wilson R, Lau $B$, Sharma $R$ and Bass $E$. Enabling patient-centered care through health information technology. 2012; Evidence Report/Technology Assessment No. 206

19. Active and Assisted Living Programme. Study concerning a Market Observatory in the Ambient Assisted Living field. 2014; http://www.aal-europe.eu/support-to-projects/marketobservatory/; retrieved January 27, 2017

20. Wild D, Kydd A and Szczepura A. Implementing digital skills training in care homes: a literature review. Nursing Older People 2016; 28, 4, p26-29; doi: 10.7748/nop.28.4.26.s22

21. Hastall $\mathrm{M}$, Eiermann $\mathrm{N}$ and Ritterfeld U. Formal and informal carers' views on ICT in dementia care: Insights from two qualitative studies. Gerontechnology 2014; 13, 1, p5156; doi: 10.4017/gt.2014.13.1.003.00 
Table 1

\begin{tabular}{|l|l|l|}
\hline Ease of use & Benefits & Barriers \\
\hline Relatively easy to use. \\
$\begin{array}{l}\text { Touchscreen can be easier to } \\
\text { learn than other input devices } \\
\text { such as a mouse. } \\
\text { Can control number of apps on } \\
\text { home screen for example to meet } \\
\text { individual needs. }\end{array}$ & $\begin{array}{l}\text { Sensitivity of the touchscreen can be } \\
\text { problematic for some - particularly } \\
\text { older people with manual dexterity } \\
\text { difficulties. }\end{array}$ \\
\hline Portability & $\begin{array}{l}\text { Brings together a range of } \\
\text { resources. } \\
\text { Easy to move between different } \\
\text { apps. }\end{array}$ & $\begin{array}{l}\text { Knowing what is useful for residents can } \\
\text { be problematic - there may be too } \\
\text { much choice. } \\
\text { An iPad might not always be available so } \\
\text { a back-up will need to be in place. }\end{array}$ \\
\hline $\begin{array}{l}\text { Can be taken to bed-bound } \\
\text { residents or passed between } \\
\text { residents to make sessions more } \\
\text { inclusive. }\end{array}$ & $\begin{array}{l}\text { Whilst relatively light it can be } \\
\text { problematic for those with manual } \\
\text { dexterity difficulties for example to hold } \\
\text { and interact with. }\end{array}$ \\
\hline Cost & $\begin{array}{l}\text { Many apps are free which can } \\
\text { result in more variety of activities } \\
\text { to meet group and individual } \\
\text { needs. }\end{array}$ & $\begin{array}{l}\text { Small size of screen might make it } \\
\text { difficult for some to use/see. }\end{array}$ \\
\hline $\begin{array}{l}\text { Initial outlay for iPads might be costly. } \\
\text { available. } \\
\text { Other tablet PCs might be less } \\
\text { expensive. }\end{array}$ \\
\hline
\end{tabular}

Table 1: Summary of the benefits and barriers

Figure 1

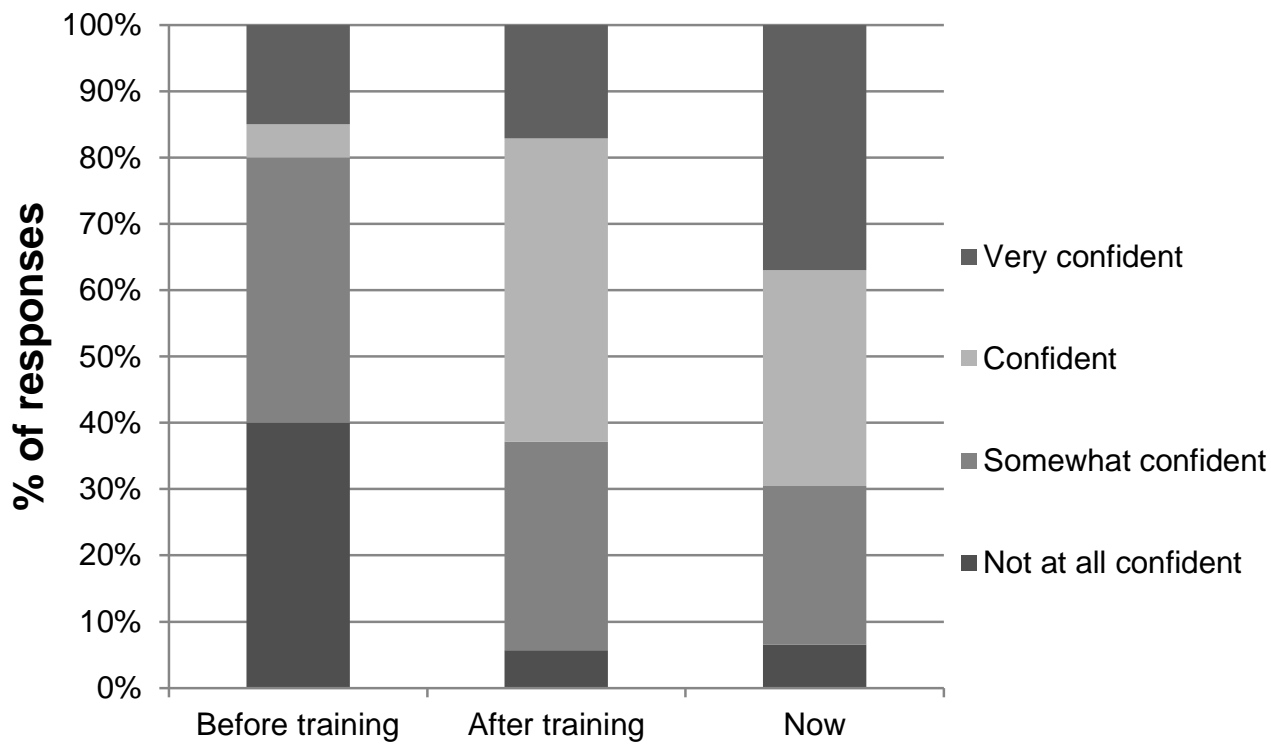

Figure 1: Self-rated confidence levels of Activity Co-ordinators at different stages of the project

Page 18 of 19 
Figure 2

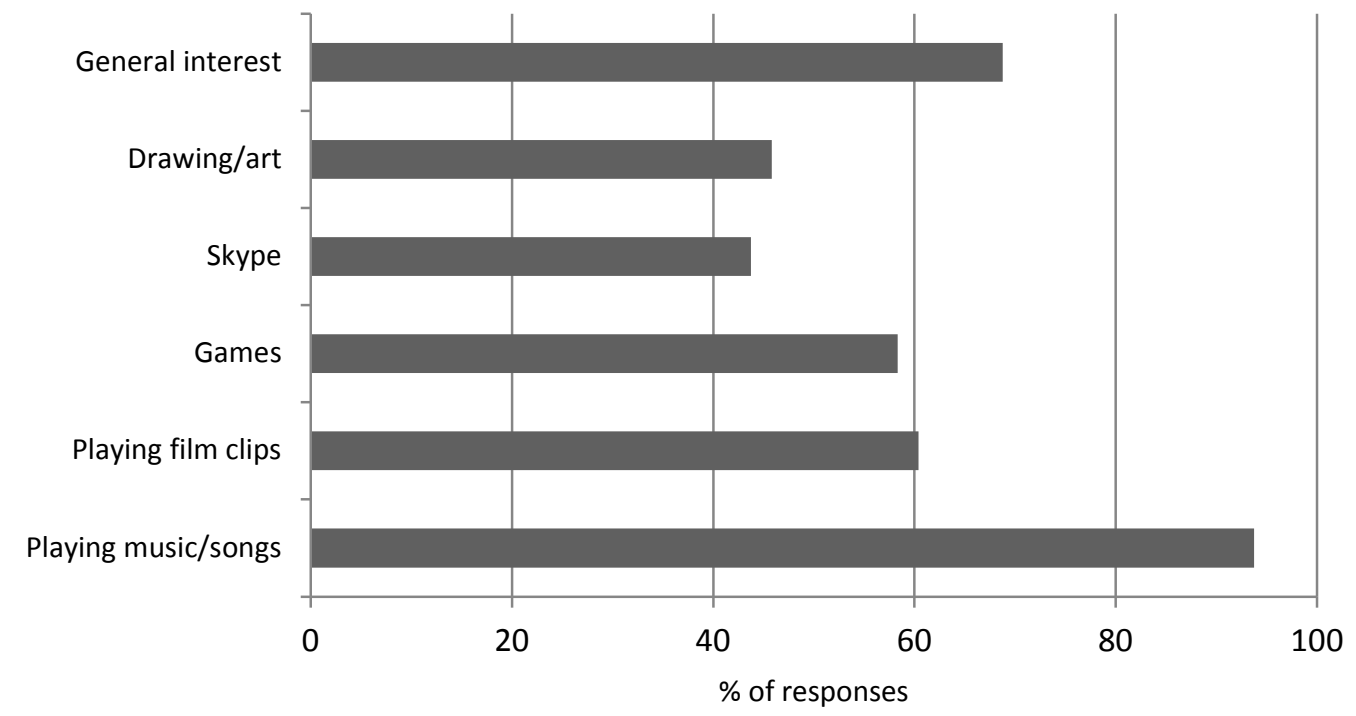

Figure 2: Activities using the iPads 